\title{
O Método de Custeio UEP como Fonte Geradora de Informações Gerenciais: Estudo Multicasos
}

Doutorado em Engenharia de Produção pela Universidade Federal do Rio Grande do

Antonio Zanin

Professor da Universidade Comunitária da Região de Chapecó - UNOCHAPECÓ Servidão Anjo da Guarda, 295-D. Efapi. Chapecó/SC. CEP: 89.809-900

E-mail:zanin@unochapeco.edu.br

Amanda Bilibio

Mestrado em andamento em Ciências Contábeis e Administração pela Universidade Comunitária da Região de Chapecó - UNOCHAPECÓ Servidão Anjo da Guarda, 295-D. Efapi. Chapecó/SC. CEP: 89.809-900 E-mail:amandabilibio@unochapeco.edu.br

Franciele Pacassa Mestrado em andamento em Ciências Contábeis e Administração pela Universidade Comunitária da Região de Chapecó - UNOCHAPECÓ Servidão Anjo da Guarda, 295-D. Efapi. Chapecó/SC. CEP: 89.809-900 E-mail: francielipacassa@unochapeco.edu.br

Carlos Cambruzzi Mestrado em andamento em Ciências Contábeis e Administração pela Universidade Comunitária da Região de Chapecó - UNOCHAPECÓ Servidão Anjo da Guarda, 295-D. Efapi. Chapecó/SC. CEP: 89.809-900 E-mail:Carlos@unochapeco.edu.br

\section{RESUMO}

O objetivo do estudo foi identificar as principais informações gerenciais que o método UEP fornece a partir da sua aplicação em indústrias do ramo alimentício. A pesquisa caracteriza-se, quanto ao objetivo, como descritiva, quanto aos procedimentos, como estudo multicasos e, quanto ao problema, como qualitativa. Para a coleta de dados, utilizaram-se entrevistas semiestruturadas, as quais posteriormente foram transcritas e analisadas com a utilização do software Atlas TI. Os achados revelaram que as principais informações gerenciais geradas por meio do método UEP estão atreladas à possibilidade de comparação dos processos e dos custos do processo fabril, identificação dos processos com maiores custos, análise de novos produtos, de projetos de investimentos, demandas de alterações de projetos de melhorias, análise da capacidade estimada. Além disso, destaca-se que o método se mostra fundamental para calcular variados índices, como a margem de contribuição, o resultado de equilíbrio, rentabilidade, produtos deficitários, permitindo a racionalização de processos e a realização de orçamentos. 
Palavras-chave: UEP. Estudo de Caso. Custos.

\section{The UEP Costing Method as a Source of Management Information: Multicase} Study

\section{ABSTRACT}

The objective of the study was to identify the main managerial information that the UEP method provides from its application in food industries. The research is characterized as the objective as descriptive, as the procedures as multicase study; and as for the problem as qualitative. For data collection, semi-structured interviews were used, which were later transcribed and analyzed using Atlas TI software. The findings revealed that the main management information generated by the UEP method is linked to the possibility of comparing the processes and the costs of the manufacturing process, identifying the processes with the highest costs, analyzing new products, investment projects, demands for changes to improvement projects, analysis of estimated capacity. In addition, it is emphasized that the method is fundamental to calculate various indices, such as contribution margin, balance result, profitability, deficit products, allowing the rationalization of processes and budgeting.

Key words: UEP. Case study. Costs.

\section{INTRODUÇÃO}

A busca por um sistema produtivo eficiente, aliado à alta produtividade e baixos custos tem se manifestado no atual cenário econômico como elemento de continuidade e manutenção do negócio, no qual o desenvolvimento adequado de um Sistema de Custeio revela-se de extrema importância, assim como a escolha do método de custos ou a combinação destes, devido à sua capacidade em prover informações relevantes ao processo decisório (Siqueira, Mazzioni, Gollo, \& Kruger, 2016).

Nesse sentido, diversos são os métodos utilizados na mensuração dos custos, sejam estes produtivos ou de prestação de serviço, dentre os quais destacam-se o Custeio por Absorção, Custeio Variável, Custeio Baseado em Atividades (ABC), Unidade de Esforço de Produção (UEP), Times Driven Activity-basead Costing (TDABC), entre outros (Wernk, Santos, Junges, \& Scheren, 2018; Mortele, Wernk, \& Zanin, 2018). 
Contudo, diante das divergências na apuração dos custos em indústrias com processo fabril diversificado, além da dificuldade para estabelecer a capacidade produtiva e realizar a comparação entre os produtos, o método UEP tem se apresentado como um dos métodos de custos mais acertados devido à sua finalidade em unificar a produção sob uma única unidade de medida comum (UEP) para o cálculo dos custos dos itens produzidos, o que tende a favorecer a simplificação do processo de controle de gestão e possibilitar a identificação dos custos unitários dos produtos (Kliemann Neto, 1994; Zanin, Magro, Levant, \& Afonso, 2019).

Ademais, frente às inúmeras informações gerenciais fornecidas e as quais se tornam base para o processo decisório, o método UEP notoriamente tem sido indicado para utilização em indústrias do ramo alimentício, devido ao amplo portfólio de produtos. Logo, diante da constatação da importância do tema, surge o questionamento: Quais as principais informações gerenciais que o método Unidade de Esforço de Produção (UEP) fornece a partir da sua aplicação em indústrias do ramo alimentício? Para responder tal problemática, tem-se como objetivo identificar as principais informações gerenciais que o método UEP fornece a partir da sua aplicação em indústrias do ramo alimentício.

Desse modo, a presente pesquisa justifica-se pela necessidade de estudos que apresentem a perspectiva dos usuários da contabilidade gerencial, na adoção do método de custos UEP em seus diferentes estágios de implementação e manutenção. A pesquisa ainda poderá contribuir para elucidar as principais informações geradas a partir da utilização do método de custos pesquisado, além de possibilitar a identificação dos benefícios ou das desvantagens proporcionados pelo método de custeio UEP. Por fim, justifica-se pela relevância do método principalmente na Região Sul do Brasil, onde, conforme Ferrari e Reis (2016), é amplamente difundido. 


\section{REVISÃO DA LITERATURA}

Neste tópico, aborda-se a base teórica que sustenta o assunto pesquisado e serve de apoio para o desenvolvimento da pesquisa empírica. Inicialmente, discorre-se sobre assuntos atrelados à temática Unidade de Esforço de Produção (UEP), sua origem e evolução. Na sequência, são contextualizadas as características do método em estudo, vantagens e desvantagens, assim como as principais informações gerenciais concebidas com sua utilização conforme pesquisas anteriores.

\subsection{Origem do Método Unidade de Esforço de Produção - UEP}

O método da Unidade de Esforço de Produção (UEP) tem suas origens na França, na época da Segunda Guerra Mundial, quando o engenheiro Georges Perrin criou um método de cálculo, alocação de custos e controle de gestão, na qual denominou suas iniciais como nomenclatura, método GP (Bornia, 2010).

A ideia de Georges Perrin era criar uma unidade de medida para medir a produção diversificada de uma fábrica em sua totalidade, já que, com o método alemão RKW, era possível criar e utilizar uma unidade de medida abstrata para medir, em uma seção homogênea, a produção diversificada (Allora \& Allora, 1995). Assim, com o objetivo de promover o método, no ano de 1951 Georges Perrin abriu uma empresa de consultoria com o nome La Méethode GP, além de publicar artigos em revistas profissionais e realizar conferências (De La Villarmois \& Levant, 2011).

Considerado o pioneiro do UEP, Georges Perrin abriu inúmeras portas para novos estudos (Allora \& Allora, 1995), tanto que, após seu falecimento em 1958, sua esposa Suzanne Perrin deu continuidade às atividades da empresa La Méthode GP e, em uma das tentativas de desenvolver o método, no dia $1^{\circ}$ de agosto de 1975 , assinou um acordo com a Les Ingénieurs Associés (LIA), onde estes não poderiam efetuar quaisquer alterações no sistema sem o acordo prévio entre as partes (Levant \& De La Villarmois, 2004). 
Nos termos do acordo, a LIA poderia continuar a promover o método, desde que o nome fosse alterado. Após a promoção do método, em 1977, este passou a ser chamado de Unité de Production (Unidade de Produção - UP). Em 1992, houve uma queda de vendas para LIA, o que necessitou uma reestruturação do método. Os consultores Jean Fiévez e Robert Zaya desenvolveram o método UP, e o campo de aplicação do método foi ampliado, levando a concentração apenas nos custos de produção. Dessa forma, em abril de 1995, o nome do método foi alterado para Unité de Valeur Ajouteé (Unidade de Valor Acrescentado - UVA) (Levant \& De La Villarmois, 2004).

Dando continuidade aos estudos do método GP, em meados de 1951, Franz Allora, um dos discípulos de Perrin, traz ao Brasil uma versão aperfeiçoada, o que acaba por dar surgimento ao método UPs, também conhecido como método Unidade de Esforço de Produção (UEPs) (Bornia, 2010). Entretanto, a aplicação do método em organizações mostrou-se possível somente após a aparição de uma empresa de consultoria na cidade de Blumenau (SC), que tinha como finalidade a implementação da ferramenta, assim como, por meio da divulgação do método em congressos e dissertações de mestrados por pesquisadores da UFSC no ano de 1986 (Bornia, 2010). Essa evolução histórica pode ser observada na Figura 1. 
1940: Georges Perrin desenvolveu o modelo GP

1951: Empresa consultoria "La Méthode GP"

1958: Suzanne Perrin segue com o negócio

1977: Reestruturação do método - UP

1995: UVA (Jean Fievez e Robert

Zava

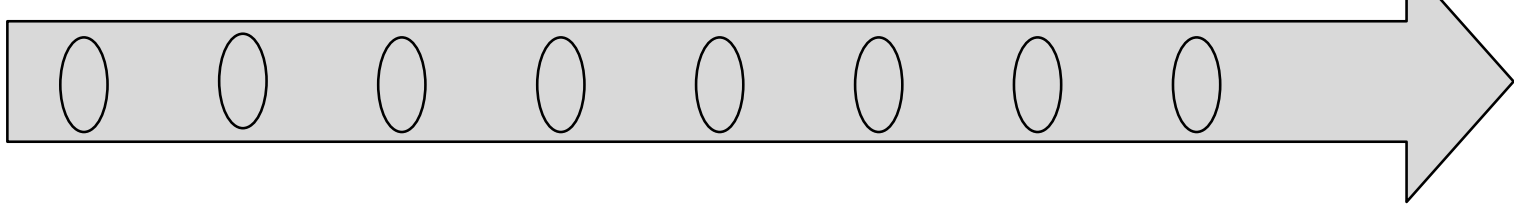

2002: Tecnosul

Consulting

1976: Empresa Tecnosul (Blumenau)

1958: Fundada a empresa Lage e Allora

1951: Franz Allora traz GP para o Brasil (UP ou UEP)

Figura 1. Evolução e desenvolvimento do método UEP

Fonte: Pereira (2015).

Diante disso, vislumbra-se um resumo da evolução histórica do método UEP desde o ano de 1940, quando o pioneiro Georges Perrin criou o método GP e como esse método se desenvolveu e se reestruturou ao longo dos anos até chegar às definições atuais.

\subsection{Unidade de Esforço de Produção - UEP}

As indústrias com uma produção diversificada possuem dificuldade não apenas em estabelecer sua capacidade produtiva, mas também em realizar comparabilidade entre os custos dos produtos, pois possuem esforços diferentes, o que dificulta uma apuração adequada e precisa (Zanin, Dal Magro, Levant \& Afonso, 2019; Afonso, Wernke \& Zanin, 2018). Dessa forma, o método de Unidade de Esforço de Produção (UEP) basicamente se fundamenta na unificação da produção, para que o processo de controle de gestão se torne mais simples. Entretanto, é por meio de custos e medidas 
físicas de eficiência, eficácia e produtividade que ocorre a mensuração do desempenho de uma determinada empresa (Bornia, 2010).

Nesse sentido, conforme expõe Pereira (2015), o método "UEP é uma metodologia de medição dos esforços empregados na produção em uma mesma unidade de medida, em ambientes de produção diversificada, com foco no conceito de custos de transformação". Basicamente, esse método fundamenta-se na determinação de uma unidade de medida comum (a UEP) para o cálculo dos custos de todos os produtos fabricados pela empresa, ao simplificar o processo de controle de gestão e possibilitar a identificação dos custos por produto (Bornia, 2010; Wernke, Junges, \& Zanin, 2019).

$\mathrm{Na}$ visão de Sakamoto (2003), o método baseia-se na noção de esforço de produção, ou seja, tudo que envolve a transformação da matéria prima: esforços realizados por uma máquina, esforço humano, de capitais e da energia aplicada direta e indiretamente. Dessa forma, o esforço total de uma fábrica é o resultado da soma de todos os esforços de produção parciais desempenhados nos Postos Operativos, os quais se caracterizam por se envolverem diretamente com os produtos, pois estes são compostos por operações de transformação homogênea, ou seja, um conjunto formado por operações produtivas, nas quais devem possuir características de serem semelhantes para todos os produtos que passam, diferenciando somente o tempo de passagem (Bornia, 2010).

Na concepção de Kliemann Neto (1994), este método racionaliza e agiliza o processo de gerenciamento e controle das atividades desempenhadas por uma unidade industrial, na qual serve como base para a implementação de sistemas de custo precisos e eficazes e para a realização das atividades de planejamento, programação e controle da eficiência de processos de produção, simplificando a gestão de processos de produção complexos.

Para Allora e Oliveira (2010), o método UEP é fundamentado em três princípios: o princípio da Constância das relações, o princípio das Estratificações e o princípio do Valor Agregado (Rotações). O princípio da Constância das Relações aborda que, 
independentemente dos tipos de variações dos preços unitários, os esforços de produção desenvolvidos pelas operações elementares de trabalho em uma indústria são interligados por relações constantes no tempo. O princípio das Estratificações fundamenta que o grau de exatidão é dependente do grau de diferenciação de cada nova estratificação de despesas em relação às precedentes. Por fim, o princípio do Valor Agregado é baseado no fato de que o lucro é a mais valia, é a parcela de dinheiro a mais que a empresa obtém vendendo o seu trabalho.

Assim, para a implantação do método, Souza e Diehl (2009) afirmam que é necessário seguir seis etapas: (1) dividir a fábrica em postos operativos (POs); (2) calcular os potenciais de produção dos POs; (3) definir um produto-base; (4) calcular o foto-custo do produto-base; (5); calcular o potencial produtivo dos postos operativos; e (6) cálculo do valor dos produtos em UEPs.

\subsection{UEP como Fonte Geradora de Informações Gerenciais}

A utilização do método UEP propicia inúmeras vantagens, sendo a principal a geração de informações gerenciais relevantes para o processo decisório nas organizações (Zanin, Magro, Levant, \& Afonso, 2019). Dentre tais informações, podemse destacar: (a) informações relativas aos custos de transformação; (b) a mensuração da produção; (c) informações acerca da lucratividade dos produtos; (d) informações acerca da composição do preço dos produtos; (e) a comparação de processos; (f) a análise das capacidades de produção; (g) informações acerca da quantidade de máquinas e pessoal utilizados; (h) a análise da eficiência do processo produtivo; (i) avaliar desempenhos; e (j) a análise da viabilidade de aquisição de novos equipamentos (Kliemann Neto, 1994; Souza \& Diehl, 2009).

Nessa perspectiva, Pereira (2015) elucida em sua pesquisa as principais utilidades do método UEP, juntamente com as possíveis decisões que podem ser tomadas com os resultados que o método fornece, as quais são apresentadas na Tabela 1. 
Tabela 1

Utilidades do método UEP e possíveis decisões

\begin{tabular}{|c|c|}
\hline Utilidades & Possíveis decisões \\
\hline $\begin{array}{l}\text { - Fornecer informações detalhadas dos custos de } \\
\text { transformação; } \\
\text { - Mensurar a produção total numa mesma unidade; } \\
\text { - Auxiliar na redução de custos; } \\
\text { - Fornecer informações dos processos de produção; } \\
\text { - Identificar atividades que não agregam valor aos } \\
\text { produtos; } \\
\text { - Detalhar informações da capacidade de produção; } \\
\text { - Identificar gargalos da produção; } \\
\text { - Permite a análise de viabilidade de aquisição de } \\
\text { novos equipamentos; } \\
\text { - Avaliar desempenhos; } \\
\text { - Fornecer informações de lucratividade e rentabilidade } \\
\text { dos produtos; } \\
\text { - Simplificar processo de administração da produção; } \\
\text { - Controlar e monitorar o processo de produção. }\end{array}$ & $\begin{array}{c}\text { - Redefinir critérios de alocação de custos; } \\
\text { - Otimizar o uso de recursos pelos POs; } \\
\text { • Reajustar salários; } \\
\text { • Reprogramar a produção; } \\
\text { - Incluir ou eliminar atividades ou redefinir } \\
\text { POs; } \\
\text { • (Re)definir preços; } \\
\text { - Rever quadro de pessoal - contratar e/ou } \\
\text { demitir; } \\
\text { - Reestruturar processos; } \\
\text { - Redefinir quantidade de } \\
\text { máquinas/tecnologia; } \\
\text { - Implementar incentivos de desempenho; } \\
\text { - Rever e otimizar o uso de recursos; } \\
\text { • Alterar mix de produtos; } \\
\text { - Replanejar processos de produção. }\end{array}$ \\
\hline
\end{tabular}

Nota. Fonte: Pereira (2015).

Ademais, é possível evidenciar que o método UEP oportuniza o conhecimento da real capacidade fabril instalada e utilizada e, consequentemente, viabiliza traçar e planejar o mix de produção a fim de maximizar a produtividade e a desburocratização. Além disso, pelo método é possível ainda apurar os custos de transformação (reduzindo distorções na alocação do custo de cada item); identificar os gargalos da produção (para tomar providências para aumentar a eficiência da fábrica) e analisar a produção em UEPs e permitir sua implantação e utilização paralelamente ao sistema vigente na empresa, sem interferências (Oenning, Neis \& Mazzioni, 2006; Allora \& Oliveira, 2010; Santana, Afonso, Zanin, \& Wernke, 2017).

Além do mais, têm-se possibilidades de mensuração de indicadores não financeiros, como a comparação do grau de dificuldade para elaboração de cada produto, conhecimento do potencial produtivo por hora dos postos operativos; 
determinação da capacidade de produção mensal da empresa e dos postos operativos; identificação de gargalos produtivos; tomar conhecimento da ociosidade da capacidade instalada de produção; mensuração do consumo de horas pela produção do mês e da ociosidade em horas dos postos operativos, além da avaliação do percentual de ociosidade do expediente mensal em cada posto operativo (Wernke \& Lembeck, 2009).

Desse modo, o método UEP apresenta-se como uma ferramenta de custo que possui diversas utilidades e fonte de inúmeras informações gerenciais que podem ser tomadas como base para possíveis decisões nas organizações, principalmente para as que possuem dificuldade na apuração precisa, causada por uma produção diversificada.

\section{PROCEDIMENTOS METODOLÓGICOS}

Esta pesquisa delineia-se de caráter descritiva, com abordagem qualitativa, uma vez que possui o intuito de expor as características de um fenômeno (Andrade, 2002), possibilitar obter as principais informações gerenciais fornecidas pelo método UEP, assim como se pode descrever a complexidade de determinado problema de estudo, analisar a interação de certas variáveis, além de compreender e classificar processos dinâmicos vividos por grupos sociais (Richardson, 1999, Beuren, 2012).

Quanto aos procedimentos, caracterizam-se como um estudo multicasos, em que se concentra nas empresas selecionadas, a fim de aprofundar os conhecimentos (Beuren, 2012), obter maior grau de generalização quanto às informações obtidas e analisar o como e porquê de determinada situação (Fonseca, 2002).

Nessa perspectiva, adotou-se como instrumento de coleta de dados a entrevista semiestruturada, a qual é considerada um dos principais instrumentos para a pesquisa qualitativa, pois possibilita maior interação entre pesquisador e entrevistado, além de valorizar mais a investigação ao facultar que 0 pesquisador desenvolva questionamentos relevantes durante a entrevista, as quais não estavam previstas na estruturação das perguntas (Beuren, 2012). A entrevista realizada foi subdivida em 
sessões, em que se abordou, inicialmente, a caracterização do respondente e, posteriormente, questões sobre Implantação, Manutenção/Rotinas e Informações Concebidas, referentes ao UEP.

Por conseguinte, os objetos de estudos consistiram em três indústrias do ramo alimentício com atuação no mercado internacional e que possuem em comum o método UEP implantado em suas unidades produtivas. A seleção das organizações pesquisadas ocorreu de maneira intencional, por acessibilidade e interesse.

As entrevistas foram aplicadas no mês de Junho de 2019, junto aos gestores de custos/contabilidade das organizações e, posteriormente, após a coleta dos dados, estes foram analisados com base na técnica de análise de conteúdo e com auxílio do Software Atlas TI, o qual possibilitou sistematizar, organizar, remontar e gerir as informações de forma criativa e sistemática.

\section{ANÁLISE DOS RESULTADOS}

As empresas participantes desta pesquisa atuam no ramo alimentício, assemelhando-se por atuarem no mercado internacional e pela utilização do método UEP na geração de informações para o processo decisório e produtivo da organização. Logo, por meio dos dados coletados, tornou-se possível investigar as principais informações gerenciais fornecidas pelo método UEP.

No que tange às indústrias pesquisadas, caracterizadas como indústria "A", indústria "B" e indústria "C", estas constituem-se como indústrias multinacionais de grande porte, que dispõem do método UEP implantado em suas unidades produtivas. A indústria $A$ atua há mais de 80 anos no mercado e possui um portfólio de mais de três mil produtos alimentícios, entre eles a produção de suíno, frangos, frios, embutidos, margarinas, pratos prontos, etc.

Já a indústria B encontra-se no mercado há 50 anos e detém plantas industriais e comerciais, em que as primeiras tratam-se de unidades de suínos, aves e leite, fábricas de ração, unidades de ativos biológicos (granjas, incubatórios e unidade de 
disseminação de genes) e, por sua vez, as plantas comerciais concernem a pontos avançados de vendas, centros de distribuição, exportação e a sede central. Por sua vez, a indústria $C$ opera há aproximadamente 47 anos no mercado, tendo sido essencialmente de natureza familiar até o ano de 2016, quando passou a integrar um grupo multinacional do segmento, o qual trabalha principalmente com biscoitos, massas, refrescos em pó e cereais.

Em relação às informações coletadas, a Tabela 2 visa apresentar uma síntese das principais características dos respondentes e das organizações em estudo.

Tabela 2

Caracterização dos objetos de estudo

\begin{tabular}{|c|c|c|c|}
\hline Indústria & Qualificação dos Respondentes & $\begin{array}{c}\mathbf{N}^{\circ} \text { de } \\
\text { Colaboradores }\end{array}$ & $\begin{array}{c}\text { Ano de } \\
\text { implantação } \\
\text { UEP }\end{array}$ \\
\hline Indústria A & $\begin{array}{l}\text { Respondente 1: Bacharel em Administração, pós- } \\
\text { graduado em Gestão Estratégica de Custos. Atua } \\
\text { na empresa há } 24 \text { anos no setor de Controladoria. } \\
\text { Respondente 2: Bacharel em Ciências Contábeis, } \\
\text { Pós-graduado em Engenharia de Produção. Atua } \\
\text { na empresa há } 17 \text { anos no setor de Controladoria. }\end{array}$ & $\begin{array}{l}\text { Mais de } 100 \text { mil } \\
\text { colaboradores }\end{array}$ & 1997 \\
\hline Indústria $B$ & $\begin{array}{c}\text { Bacharel em Ciências Contábeis. Atua no } \\
\text { Departamento de Controladoria. }\end{array}$ & $\begin{array}{l}28 \text { mil } \\
\text { colaboradores }\end{array}$ & 2007 \\
\hline Indústria C & $\begin{array}{c}\text { Bacharel em Ciências Contábeis, Pós-graduado } \\
\text { em Controladoria e Direito Tributário. Atua há } 21 \\
\text { anos. }\end{array}$ & $\begin{array}{c}3.800 \text { mil } \\
\text { colaboradores }\end{array}$ & 2013 \\
\hline
\end{tabular}

Nota. Fonte: Dados da Pesquisa.

No tocante aos respondentes da pesquisa, verifica-se que todos detêm formação em Ciências Contábeis ou Administração, com posterior qualificação na área de Custos, assim como exercem, há muito tempo, atividades associadas a custos/controladoria nas organizações em estudo, além de possuírem experiência no processo de implementação ou manutenção do método de custos UEP. Ademais, constata-se que o tamanho da organização está diretamente associado ao ano de implantação do 
método, fato que possivelmente ocorre pelas necessidades de informações em níveis mais amplos ao processo decisório, quantidade de operações para controlar custos e conhecimento de métodos e custos produtivos com apuração mais justa.

Realizada a caracterização inicial das empresas e respondentes participantes da pesquisa, apresenta-se, na sequência, a análise descritiva dos dados, momento em que se infere sobre as principais informações gerenciais utilizadas por meio do uso do método UEP nas organizações objeto de estudo. Os resultados obtidos foram analisados sob base de três concepções, as quais correspondem às subdivisões de temas tratados na entrevista. Dentre estes, apontam-se Implantação, Manutenção/Rotinas e Informações Concebidas.

Por meio da Figura 2, é possível observar os principais relatos dos entrevistados a respeito da concepção Implantação.

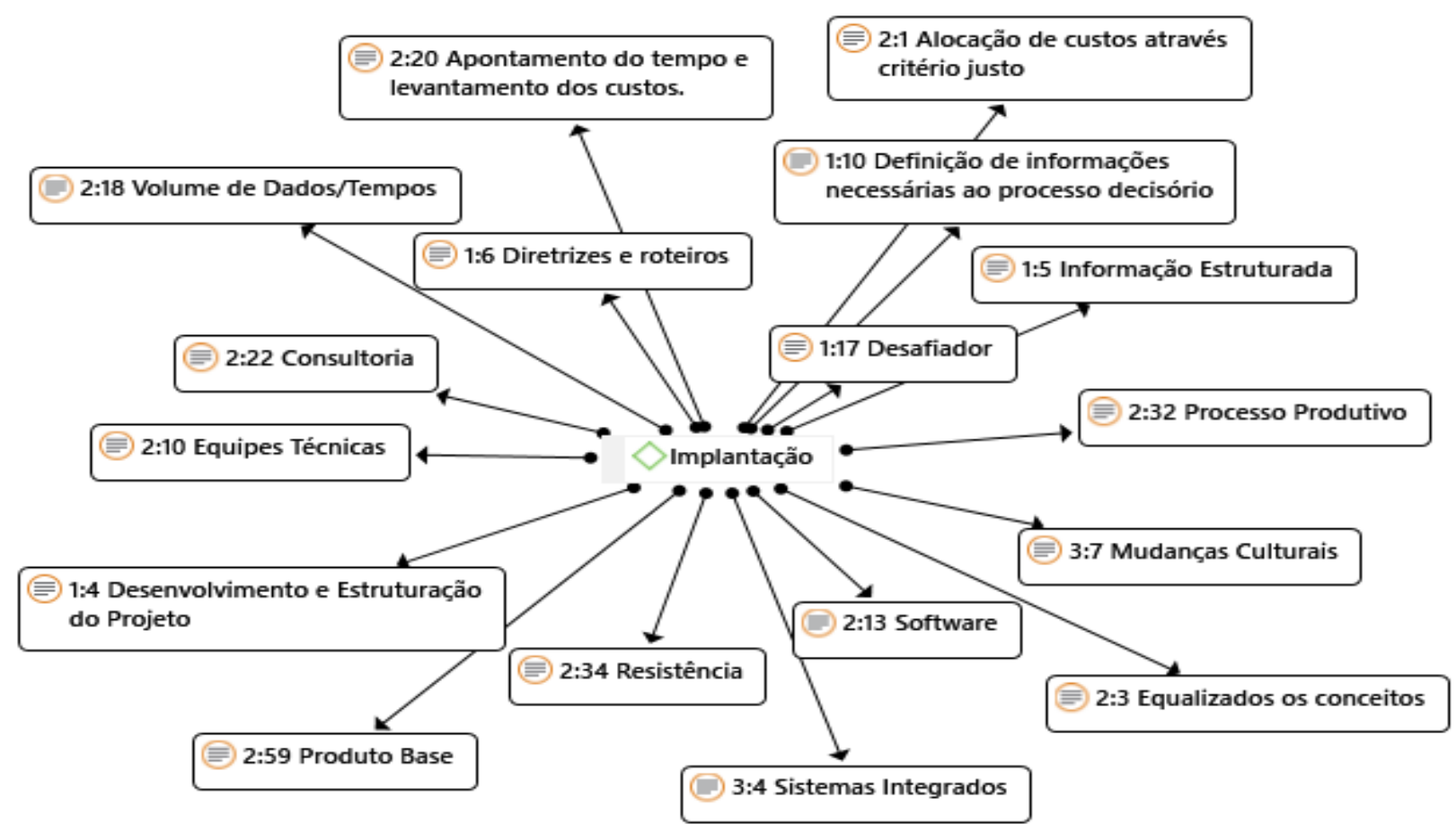

Figura 2. Concepção Implantação

Fonte: Dados da Pesquisa. 
Mediante os achados, é possível averiguar que o conhecimento do método UEP e sua implantação nos processos produtivos ocorreu em períodos distintos nas organizações estudadas. Na indústria A, a implantação teve início no ano de 1997, devido a dificuldades na alocação dos custos aos processos produtivos, complexidade dos processos e esforços distintos dos produtos, o que acabou por evidenciar que a utilização de um método adequado pode afetar diretamente a rentabilidade dos demais itens. Ademais, conforme os respondentes, apesar de existir um processo de implantação, foi apenas em 2010 que colaboraram de modo mais ativamente deste, devido à aquisição de uma nova empresa, o que necessitou a equalização de conceitos e finalização do sistema das demais unidades produtivas.

Não obstante, no que tange à escolha do método UEP, os respondentes da indústria $\mathrm{A}$ afirmam que todos os métodos de custos possuem pontos fortes e pontos fracos, porém o UEP mostrou-se um método justo, que valoriza os produtos pelo esforço. Ainda declaram que este método apropria o custo da forma mais correta possível, pois há produtos que possuem um processo muito longo, além de matériasprimas que podem dar origem ou compor a produção de diversos itens.

Por sua vez, ao analisar a indústria $B$, observa-se que o método UEP foi adotado ao revelar-se mais eficaz frente às necessidades de informações estruturadas para direcionamento do custo fixo, além do fato de os demais métodos necessitarem de alto nível de demanda e por, principalmente, focarem em uma informação empírica e não na informação coletada ou real, o que proporcionaria uma comparabilidade mais adequada. Em outras palavras, a empresa contava com um índice de custo fixo, todavia não havia critérios adequados que sustentavam o mesmo; logo, como o respondente afirma, "não era uma informação construída que fosse de fácil acesso para que os outros usuários pudessem usá-la para tomar algum tipo de decisão ou realização de algum cálculo".

Assim, a implantação do método UEP na indústria $B$, conforme relatado, teve seu início no ano de 2007 em uma das unidades produtivas com maior complexidade, o que possibilitou visualizar inúmeros desafios, auxiliar na definição de premissas e 
informações desejadas pelos gestores para o processo decisório. Referente à participação do respondente da indústria $B$, este evidencia que participou de todos os processos desde apuração de cronoanálise (cronometragem), construção dos roteiros de fabricação, além da definição dos principais pormenores, das premissas básicas de implantação e de informações que seriam requeridas por meio do sistema.

Quanto à indústria $C$, estes necessitavam de um método de custeio, visto que não dispunham de nenhum sistema de custo gerencial; logo, a metodologia do UEP mostrou-se muito apropriada para o estilo de trabalho e o ramo de atividade da indústria citada, por obter várias linhas de produção, na qual o mesmo produto era fabricado em mais de uma linha, com tempos, capacidade de produção e consumos diferentes entre si, o que gerou a necessidade em obter a informação dos custos do mesmo produto em cada uma das linhas.

Cabe apontar que a indústria $C$ optou por não integrar o sistema com o UEP ao software interno; logo, trabalha-se de forma separada ao realizar-se o carregamento das informações via Excel e arquivos, ou seja, utilização de dados de valores da contabilidade e informações de ordens produtivas do ERP. Ademais, é possível frisar que o respondente da indústria $C$ liderou toda a equipe interna quando o método UEP foi implantado no ano de 2013; todavia, assim como as demais empresas, sempre dispunha do auxílio de consultores especializados. Por conseguinte, para a implementação do método UEP, ressalta-se a extrema importância da existência de uma departamentalização acertada dentro da organização que possibilite identificar o custo, alocar a despesa para então gerar um índice.

Nesse sentido, convém salientar que, para a implementação do método, embora a equipe de trabalho seja exclusivamente interna, as indústrias pesquisadas necessitaram buscar empresas ou pessoas com conhecimentos técnicos, para proporcionar suporte na definição e elaboração do projeto, fornecimento de software e consultoria. Ainda referente às equipes de trabalho, estas variaram de 2 a 3 pessoas, conforme a complexidade da unidade e processo, uma vez que possuem a medição 
dos esforços produtivos (tempo), o que ocasiona grandes volumes de dados para processamento e análise.

Não obstante, constatou-se que as organizações adotam a utilização de um produto base com o maior número de elementos de custos, que permitem gerar um índice base para transformar reais em UEP. Associada a isso, tem-se a demanda de esforço na coleta de dados de custos dos produtos, tempos e processos, os quais, depois de estruturados, necessitam manutenção e atualização. Além disso, diante de tais mudanças, como aponta o entrevistado da indústria $A$, podem surgir resistências ao processo devido ao não conhecimento e à cultura instalada. Todavia, os colaboradores tendem a aceitar devido às vantagens atreladas à resolução de problemas de cálculos.

Já em relação à concepção Manutenção do Método UEP nas organizações pesquisadas (Figura 3), as mesmas enalteceram, em suas respostas, o processo de manutenção do sistema de custos, desafiador e de alta capacidade de geração de informações. 


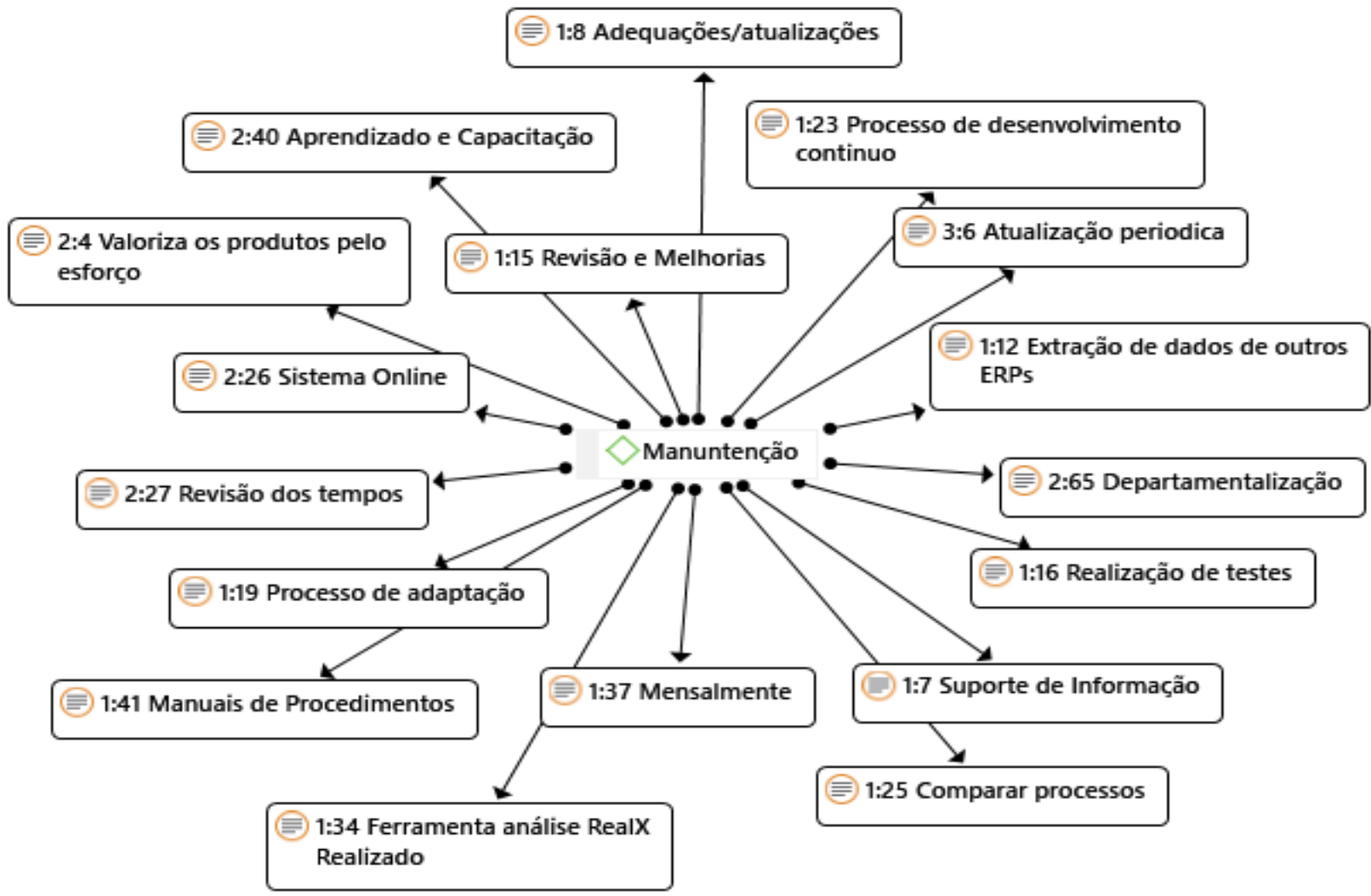

Figura 3. Concepção Manutenção

Fonte: Dados da Pesquisa.

Nesse sentido, diante dos dados apresentados, verifica-se que, para a indústria A, não existe um método tido como o mais correto e preciso na apuração dos custos produtivos, uma vez que todos possuem pontos fracos e fortes, porém a UEP mostrouse o sistema mais justo: valoriza os produtos pelos esforços corretos despendidos. Quanto ao sistema de cálculo de custos, os respondentes enunciaram que este é online; apesar disso, o cálculo do UEP e seu carregamento é realizado offline, por ser este realizado mensalmente. Ademais, corrobora-se a necessidade de realizar manutenção e acompanhamento dos tempos e custos.

O entrevistado da indústria $B$ acrescenta a necessidade de atualizar constantemente os processos dentro do UEP e levantamento de tempos, a fim de não prejudicar a comparabilidade dos processos e os custos dos produtos. Por sua vez, 
referente aos processos de implantação e manutenção, estes foram tidos como desafiadores, uma vez que as informações geradas serviram de suporte aos gestores.

Logo, diante de tal perspectiva, as organizações sob estudo ressaltaram a importância da criação e utilização de manuais, além da necessidade constante de ser efetuada reciclagem nas áreas corporativas, ou seja, conversar e direcionar os colaboradores quanto às dúvidas existentes, além do acompanhamento contínuo do método que deve ser realizado.

Por fim, quando questionados sobre as informações geradas pela UEP, é possível observar, por meio da Figura 4, os principais pontos destacados pelos respondentes.

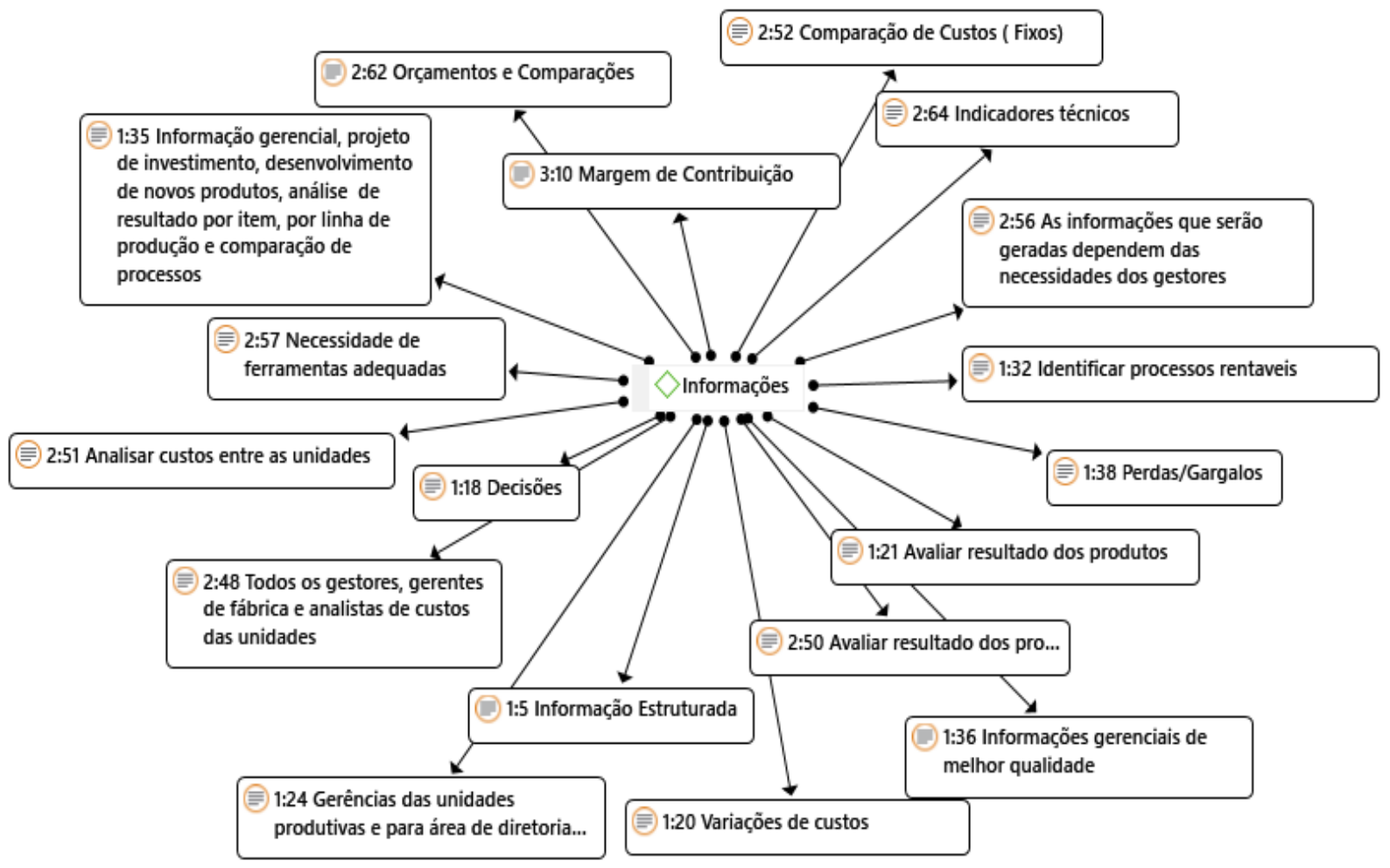

Figura 4. Concepção Informações

Fonte: Dados da Pesquisa

A partir das informações dispostas acima, pode-se evidenciar a possibilidade de o método UEP gerar informações estruturadas para o processo decisório, constituindo- 
se uma ferramenta que permite analisar a capacidade estimada do realizado; identifica com qualidade as variações e mensura apropriadamente a capacidade.

Diante de tal perspectiva, as organizações pretendem dar continuidade na utilização do método para comparar processos e custos do processo fabril, uma vez que apesar das unidades produtivas possuírem esforços de produção similares, estas englobam custos fixos unitários diferentes devido ao seu porte. Assim a estrutura de apoio acaba por tornar-se mais pesada para uma unidade pequena do que para uma unidade de porte maior. Com isso, a UEP viabiliza identificar os processos que têm maior custo e que, independentemente do aumento da produção, irão continuar a gerar perdas de competitividade. Além disso, o método permite aperfeiçoar as informações gerenciais desde a análise de investimentos de projetos, demandas de alterações de projetos de melhorias, alteração dentro da fábrica. Não obstante, a UEP mostra-se como parâmetro não apenas na tomada de decisão, mas também na análise de novos produtos (custo fixo e variável envolvido).

Tendo em vista tal fato, as indústrias destacam que as informações geradas não são utilizadas apenas pelos altos gestores, mas também mostram-se essenciais para 0 cálculo da margem de contribuição, o resultado de equilíbrio, rentabilidade, produtos deficitários, além de permitirem racionalizar processos e realizar orçamentos. Porém, este processo de mudança e adaptação requer empenho, conhecimento e capacitação constante, adaptação às mudanças e resolução de problemas.

\section{CONSIDERAÇÕES FINAIS}

Ao se considerar os ambientes empresariais nos quais as organizações estão inseridas, a adoção de ferramentas de gestão que propiciem informações mais relevantes e acuradas tornou-se de extrema relevância. Nessa perspectiva, esta pesquisa teve como principal objetivo identificar as principais informações gerenciais que o método UEP fornece a partir da sua aplicação em indústrias do ramo alimentício. 
Diante dos vários métodos de custeio, o método UEP apresenta-se como um dos métodos viáveis e indicado para indústrias do ramo alimentício com produção diversificada, visto que diante um amplo portfólio de produtos, o método proporciona levantar inúmeras informações gerenciais consideráveis à frente da unificação da produção, de modo a permitir análises para tomada de decisões mais assertivas.

Destarte, a partir do objetivo do estudo, constatou-se que entre as informações gerenciais fornecidas por intermédio do uso do método UEP, as principais citadas pelos respondentes estão a comparação dos processos e dos custos do processo fabril, a análise dos processos que possuem maior custo, a análise de novos produtos, de projetos de investimentos, de demandas de alterações de projetos de melhorias, análise da capacidade estimada do realizado além de possíveis alterações a serem realizadas dentro das indústrias.

Ressalta-se ainda, que além de informações gerenciais, os respondentes afirmam que o método mostra-se fundamental para calcular vários índices, como a margem de contribuição, o resultado de equilíbrio, rentabilidade, produtos deficitários, além de oportunizar a racionalização de processos e realização de orçamentos.

Vale salientar que os respondentes das três indústrias em estudo, afirmaram não dispor de fundamentos para abdicar o método UEP, pelo contrário, apresenta-se motivos para ampliar e desenvolver o método cada vez mais devido aos benefícios que o mesmo oferece nessas organizações.

Por fim, conclui-se que o objetivo do estudo tenha sido alcançado mediante apresentação das principais informações gerenciais fornecidas a partir da usabilidade do método UEP, na qual apresenta-se imprescindível nas indústrias pesquisadas, devido seu amplo portfólio de produtos.

\section{REFERÊNCIAS}

Afonso, P. S. L. P., Wernke, R., \& Zanin, A. (2018). Managing the cost of unused capacity: an integrative and comparative analysis of the abc, tabc and uep methods. Revista del instituto internacional de costos, 13, 150-163. 
Allora, F., \& Allora, V. (1995). UP’ Unidade de Medida da Produção. São Paulo: Livraria Pioneira Editora.

Allora, V., \& Oliveira, S. E. (2010) Gestão de custos: metodologia para a melhoria da performance empresarial. Curitiba: Juruá.

Andrade, M. M. (2002). Como preparar trabalhos para cursos de pós-graduação: noções práticas. (5a ed). São Paulo: Atlas.

Beuren, I. M. (Org.). (2012). Como elaborar trabalhos monográficos em contabilidade. (3a ed). São Paulo: Atlas.

Bornia, A. C. (2010) Análise Gerencial de Custos: aplicação em empresas modernas. (3a ed). São Paulo: Atlas.

De La Villarmois, O., \& Levant, Y. (2011). From adoption to use of a management control tool: case study evidence of a costing method. Journal of applied accounting research, 12(3), 234-259.

Ferrari, M. J., \& Reis, L. S. (2016). Princípios na gestão de custos: uma reflexão teórica acerca dos fundamentos epistemológicos dos modelos de equivalência. Anais do Congresso Brasileiro de Custos-ABC. Porto de Galinhas, PE, Brasil, 23.

Fonseca, J. J. S. (2002). Metodologia da pesquisa científica. Fortaleza: UEC.

Kliemann Neto, F. J. (1994). Gerenciamento e controle da produção pelo método de esforço de produção. Anais do Congresso Brasileiro de Gestão Estratégica de Custos, São Leopoldo, RS, Brasil.

Levant, Y., \& de La Villarmois, O. (2004). Georges Perrin and the GP cost calculation method: the story of a failure. Accounting, Business \& Financial History, 14(2), 151181.

Oenning, V., Neis, D. R., \& Mazzioni, S. (2006). Apuração e gestão de custos pelo método das unidades de esforço de produção: UEP. Anais Congresso Brasileiro de Custos, Belo Horizonte, 13.

Pereira, S. I. M. (2015). Custeio por atividades (ABC) e unidade de esforço de produção (UEP): similaridades, diferenças e complementaridades (Doctoral dissertation, Universidade de São Paulo). Perrin, G., Perrin, S., \& Peugeot, F. (1971). Prix de revient et contrôle de gestion par la méthode GP. Tradução J. Bronte Chueca Dunod. 
Richardson, R. J. (1999). Pesquisa social: métodos e técnicas. (3a ed). São Paulo: Atlas.

Sakamoto, F. T. C. (2003). Melhoramento nas ferramentas de gestão de custo e produção: implantação, sistematização e utilizações da UP, Unidade de Produção, na Seara Alimentos S. A. Anais Congreso del Instituto Internacional de Costos, 8, Punta del Este (Uruguai).

Santana, A. F. B., Afonso, P. S. L. P., Zanin, A., \& Wernke, R. (2017). Costing Models for Capacity Optimization in Industry 4.0. Anais 7th Manufacturing Engineering Society International Conference, 13, 1183-1190.

Siqueira, M. V., Mazzioni, M., Gollo, V., \& Kruger, S. D. (2016). Custeio por absorção x UEP: análise comparativa dos custos em uma indústria de confecções. Anais do Congresso Brasileiro de Custos, Porto de Galinhas - PE, Brasil, 23.

Souza, M. A., \& Diehl, C. A. (2009). Gestão de custos: uma abordagem integrada entre contabilidade, engenharia e administração. São Paulo: Atlas.

Wernke, R., \& Lembeck, M. (2009). Indicadores não-financeiros do método UEP aplicados na gestão fabril. Anais do Congresso Brasileiro de Custos - ABC, Fortaleza, CE, Brasil, 16.

Wernke, R., Santos, A. P., Junges, I., \& Scheren, G. (2018). Comparação do custo fabril apurado pelos métodos Unidades de Esforço de Produção (UEP) e Time-driven Activity-based Costing (TDABC): estudo de caso em linha de produção de frigorífico. Exacta, São Paulo, v. 16, n. 3, p. 103-119.

Wernke, R., Junges, I., \& Zanin, A. (2019). Mensuração da ociosidade fabril pelos métodos ABC, TDABC e UEP. Revista Contemporânea de Contabilidade, 16(38), 185-206.

Zanin, A., Dal Magro, C. B., Levant, Y., \& Afonso, P. S. L. P. (2019). Potencialidades gerenciais do Método UEP (Unidade de esforço de produção). Anais Congreso Internacional de Costos, Mendoza, Argentina, 16.

Data de Submissão: 24/11/2019

Data de Aceite: 16/12/2019 